\title{
RECENT UPDATE ON PRONIOSOMAL GEL AS TOPICAL DRUG DELIVERY SYSTEM
}

\author{
JAMPALA RAJKUMAR*, RADHA GV, TRIDEVA SASTRI K, SADHANA BURADA
}

Department of Pharmaceutics, Gitam Institute of Pharmacy, Gitam (Deemed to be University), Rushikonda, Visakhapatnam - 530 045, Andhra Pradesh, India. Email: jampalarajkumar@gmail.com

Received: 19 July 2018, Revised and Accepted: 17 September 2018

ABSTRACT

An existence of transdermal delivery tool, proniosomal gel, has established to showed remarkable development for lipophilic/hydrophilic drugs over additional formulations. Newer drugs of lipophilic nature emerge poor bioavailability, irregular absorption, and pharmacokinetic changes. Therefore, this novel drug delivery system has been proved advantageous over other oral and topical delivery of drug candidates to bypass such disruption. This proniosomal gel basically is a compact semi-solid liquid crystalline (gel) composed of non-ionic surfactants easily formed on dissolving the surfactant in a minimal amount of acceptable solvent and the least amount of aqueous phase and phosphate buffer. Topical application of gel under occlusive condition during which they are converted into nisomes due to hydration by water in the skin present itself. Proniosomal gels are typically present in transparent, translucent, or white semisolid gel texture, which makes them physically stable throughout storage and transport. This review provides an important overview of the preparation, formulation, evaluation, and application of proniosome gel as a drug delivery carrier.

Keywords: Vesicular drug delivery, Proniosomal gel, Non-ionic surfactants, Coacervation phase separation, Topical drug delivery.

(C) 2019 The Authors. Published by Innovare Academic Sciences Pvt Ltd. This is an open access article under the CC BY license (http://creativecommons. org/licenses/by/4. 0/) DOI: http://dx.doi.org/10.22159/ajpcr.2019.v12i1.28558

\section{INTRODUCTION}

At the time of the ancient day's humans used cool water, a leaf, dirt, or mud was their first soothing application purpose. Understands the inherent tendency of nature, birds, and animals continued to struggles genesis of mesapatonia, practicing the treatment by the pharmacist and share his knowledge for the benefit of suffered people. Tablets were used for illness, different routes of administration available for successive delivery of designed dosage forms [1]. Development of a formulation depends on the characterization of the active ingredient. Oral administration is a most preferred route with high patient compliance. However, bioavailability is poor progress observed reasons behind were poor solubility of drug candidate followed by less absorption [2]. Less aqueous solubility is the major drawback encountered with the formulation design of new chemical moiety [3]. Recent research focused on the development of hydrophobic active pharmaceutical ingredients [4] and reported that around $40 \%$ of new drugs showed poor aqueous solubility [5]. Different techniques have been used to improve solubility and better dissolution rates of poorly water-soluble drugs which include as particle size reduction, nano ionization, cosolvency, hydrotropy, $\mathrm{pH}$ adjustment, sono crystallization, supercritical fluid process, solid dispersion, inclusion complexation, self-emulsifying or self-micro emulsifying systems, and liquisolid methods [6]. A number of novel drug delivery systems have emerged in various routes of administration, to achieve controlled and targeted drug delivery. Encapsulation of the drug in vesicular structures is one such system, and a number of vesicular drug delivery systems such as liposomes, niosomes, transfersomes, and pharmacosomes were developed [7]. Oral solid dosage forms face problems such as gastric drug/enzyme instability and first-pass metabolism. Oral route has any further problems such as an unpleasant taste, odor, and color. Transdermal dosage forms, an alternative to conventional dosage formulations, are becoming popular due to their exclusive advantages. Improved bioavailability, controlled absorption, extra uniform plasma levels, painless and reduced side effects easy application [8]. However, benefits from the transdermal route, disadvantages of their formulations such as ointments, creams, and lotions with many disadvantages with sticky in nature, poor spreadability, and concerned about its stability issue.

Topical administration is the most preferred route for local delivery of therapeutic agents due to its convenience and easy access. The specific challenge of designing a therapeutic system is to achieve an optimal concentration of a certain drug at its site of action for an appropriate time span [9]. Vesicular drug delivery systems are novel means to increase the bioavailability of the enclosed drug with more advantages over than the conventional dosage forms. Liposomes were first in such type of delivery systems, but it was not so successful due to their several drawbacks [10]. Niosomes or non-ionic surfactant vesicles are a microscopic lamellar structure of size range 10-1000 nm consisting of spherical, uni- or multi-lamellar and polyhedral vesicles in aqueous media [11]. Butnoisomes exhibits physicochemical stability problem on storage of dispersion, for example, aggregation, fusion, drug leakage or hydrolysis of the active compounds, thus raising concerns over their adoption [12]. Proniosomes were prepared as a dry powder for reconstitution before use by preserving the physical and chemical integrity of vesicles [13]. For transdermal delivery proniosomes were prepared as gel-like concentrated niosomes suitable for topical application [14]. Proniosomes are semisolid, liquid crystal (gel) product of nonionic surfactant which on hydration converts into niosomes $[15,16]$. Proniosomes when applied onto the skin surface transform into niosomes due to the hydration by water from the skin which would provide an occlusive condition and offer a potential for drug delivery through the transdermal route. The gel property of proniosomes maintaining better skin penetration and physicochemical properties. Both phospholipids and non-ionic surfactants in proniosomes can act as penetration enhancers since it was found that some phospholipids are able to fluidize the stratum corneum lipid bilayers and disperse through them [17]. Proniosomal gels are typically presentin transparent, translucent, or white semisolid gel texture, which makes them physically stable throughout storage and transport. The present article is elaborate an extensive review covering components used for proniosomal gel formulation combined with its formulation overview and biopharmaceutical parameters of the published research works on a proniosomal gel with distinct pharmaceutical products.

\section{FORMULATION INGREDIENTS CONCERN}

In spite of phospholipids and non-ionic surfactants in proniosomes can act as Penetration enhancers, since it was found that some phospholipids are able to fluidize the stratum corneum lipid bilayers and diffuse through them [17], whereas cholesterol gives stability and permeability to the vesicles. 


\section{Surfactants}

It is acting as solubilizers, wetting agents, emulsifiers, and permeability enhancers [18]. Chiefly non-ionic surfactants were used in the formulation of proniosomal gel. Based on the hydrophile-lipophile balance (HLB) values of the available surfactants, mainly categorized into w/o emulsifying agent (HLB 3-8) and o/w emulsifying agent (HLB 8-16) [19] usually the HLB value of 4-8 will give the vesicles with high compatibility. List of common nonionic amphiphiles used in proniosome formulations were mentioned in Table 1 [20].

\section{Lecithin}

Mainly acts as membrane stabilizers mostly used two varieties, i.e., Soya lecithin and egg lecithin former one collected from the soya beans later from the egg yolk [21]. Following materials were used.

- Soya lecithin.

- L- $\alpha$-egg phosphatidyl choline.

- 1-2-dimyristoyl-snglycero-3-phosphocholine.

- 1-2-distearoyl-snglycero-3phosphocholine.

- Dipalmitoylphosphatidylcholine [22].

\section{Cholesterol}

It is an important component used in the design of proniosomes which gives stability and penetrability to the vesicles. Entrapment efficiency (EE) depends on the concentration of cholesterol used. Cholesterol may reinforce bilayer assembly; vesicles cannot be built without the addition of cholesterol, with higher concentrations of cholesterol decreasing the time required for niosome assembly. It prevents accumulation by the inclusion of molecules that stabilize the system against the formation of an aggregate by repulsive steric or electrostatic effects [23].

\section{Solvent and aqueous phase}

Alcohol has shown a great effect on vesicle size and drug permeation rate of a proniosomal formulation. Different size of vesicles formed using different alcohols as they follow the order:Ethanol>propanol> butanol>isopropanol. Phosphate buffer 7.4, 0.1\% glycerol, hot water is used as the aqueous phase in preparation of proniosomes [24].

\section{Carrier material}

The use of maltodextrin based proniosomes preparation permitted flexibility in the ratio of surfactant and other components which can be incorporated [25]. In addition to this; it increases the surface area and hence efficient loading. The carriers should be safe and non-toxic, freeflowing, poor solubility in the loaded mixture solution and good water solubility for ease of hydration. Commonly used carriers are listed, they are sorbitol, mannitol, glucose, lactose, and sucrose stearate [15]; habitually used carriers are listed below [26].

a. Maltodextrin.

b. Sorbitol.

c. Spray dried lactose.

d. Glucose monohydrate.

e. Lactose monohydrate.

f. Sucrose stearate.

\section{Drug}

The drug selection criteria could be based on the following assumptions.

1. The low aqueous solubility of drugs.

2. High dosage frequency of drugs.

3. Short half-life.

4. Controlled drug delivery suitable drugs.

5. Drugs are having more adverse effects [27].

\section{Advantages}

- Proniosomes were easily prepared and did not require special conditions of storage as like other vesicular systems [28].

- Shows high EE.

- They can carry both hydrophilic and hydrophobic drugs.

- Extensively used in drug targeting for controlled release.

- Easy to handle, storage, and transportation.

\section{Classification of proniosomes}

In general, proniosomes were divided into the following types [29].

1. Semi-solid liquid crystal gel.

2. Dry granular powder Fig. 1.

\section{Methods of preparation of proniosomal gel}

a. Coacervation phase separation.

b. Slow spray coating method.

c. Slurry method.

\section{Coacervation phase separation}

Proniosomal formulae were prepared by a method reported by Alsarra et al. [30] with slight modification, using different types of nonionic surfactants, lecithin, and cholesterol. Appropriate amounts of proniosomal components mixed together with the drug were mixed with $2.5 \mathrm{ml}$ of absolute ethanol in a clean and dry, wide-mouth glass tube. After mixing all the ingredients, the open end of the glass tube was covered with a lid to prevent loss of solvent from it and warmed in a water bath at $65 \pm 3^{\circ} \mathrm{C}$ for $\sim 5 \mathrm{~min}$, until the surfactants were dissolved completely. Then, $1.6 \mathrm{ml}$ of $\mathrm{pH} 7.4$ phosphate buffer was added, and warming was continued on the water bath for $\sim 2$ min till a clear solution was observed. The mixture was allowed to cool down at room temperature until the dispersion was converted to a proniosomal gel $[31,32]$.

\section{Slurry method}

carrier material to a $250-\mathrm{ml}$ flask and the entire volume of surfactant solution was added the flask to form the slurry. If the surfactant solution volume is less, then additional organic solvent can get slurry. The flask was attached to a rotary evaporator was applied until the free-flowing. The flask was removed from the evaporator and kept under vacuum overnight. The proniosome powder was stored in sealed containers at $4^{\circ} \mathrm{C}$. The time required to produce proniosomes is independent of the ratio of surfactant solution to the carrier material and appears to be scalable [33-35].

\section{Slow spray - coating method}

This method involves preparation of proniosomes by spraying surfactant in an organic solvent onto carrier material and then evaporating the solvent. Since the carrier is soluble in the organic solvent, it repeats the process until the desired has been achieved. The surfactant coating on the carrier is very thin, and hydration of this coating allows multilamellar when the carrier dissolves [36,37]. The resulting noisome is very similar to those produced by conventional methods, and the size distribution is more uniform. It is suggested that this formulation would provide hydrolysis for hydrophobic drugs formulation [38].

\section{EVALUATION OF PRONIOSOMES}

$\% \mathrm{EE}$

Proniosomal gel $(0.2 \mathrm{~g})$ was reconstituted with $10 \mathrm{ml}$ of $\mathrm{pH} 7.4$ phosphate buffer in a glass tube. The aqueous suspension was sonicated in a sonicator bath for $30 \mathrm{~min}$. The naproxen containing niosomes were separated from the untrapped drug by centrifuging at $9000 \mathrm{rpm}$ at $4^{\circ} \mathrm{C}$ for $45 \mathrm{~min}$. The supernatant was taken, and the drug concentration in the resulting solution was assayed by ultraviolet (UV) spectrophotometer at a specific wavelength. The percentage of drug encapsulation was calculated by the following equation:

$\mathrm{EE} \%=[(\mathrm{Ct}-\mathrm{Cf}) / \mathrm{Ct}] \times 100$

Where $\mathrm{Ct}$ is the concentration of a total drug and $\mathrm{Cf}$ is the concentration of a free drug $[15,39]$.

\section{Vesicle size and zeta potential analysis}

The mean vesicle size, size distribution, and zeta potential were determined using a Dynamic Light Scattering technique by MalvernZetasizer (Nano ZS90). In a glass tube, 0.2 g proniosome gel was diluted with $10 \mathrm{ml}$ of pH 7.4 phosphate buffer. The vesicle measurements were 


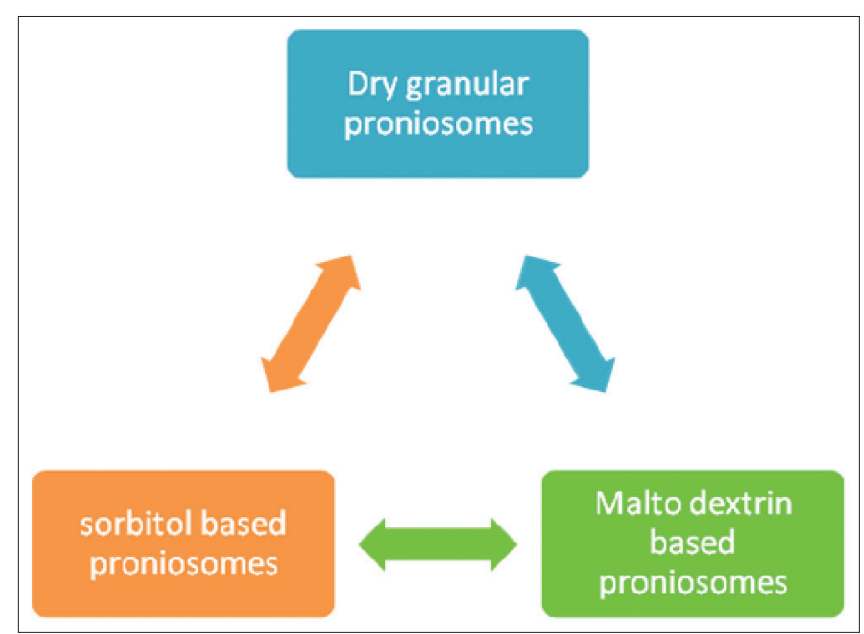

Fig. 1: Types of dry granular proniosomes

Table 1: Examples of different non-ionic surfactants

\begin{tabular}{ll}
\hline $\begin{array}{l}\text { Non-ionic } \\
\text { amphiphiles }\end{array}$ & Examples \\
\hline $\begin{array}{l}\text { Alkyl ethers and } \\
\text { alkyl glyceryl ethers }\end{array}$ & $\begin{array}{l}\text { Polyoxyethylene 4 lauryl ether (Brij 30) } \\
\text { Polyoxyethylene cetyl ethers (Brij 52, 56, 58) } \\
\text { Polyoxyethylene stearyl ethers (Brij 72, 76) }\end{array}$ \\
$\begin{array}{l}\text { Sorbitan fatty acid } \\
\text { esters }\end{array}$ & $\begin{array}{l}\text { Span 20, 40, 60, 80 } \\
\text { Polyoxyethylene } \\
\text { fatty acid esters }\end{array}$ \\
\hline
\end{tabular}

done at a temperature of $25 \pm 0.5^{\circ} \mathrm{C}$. The polydispersity index (PI) was determined as a measure of homogeneity. PI is obtained as:

$\mathrm{PI}=(\mathrm{SD} /$ vesicle size $)$.

Small values of PI $(<0.1)$ indicate a homogeneous population, while PI values $>0.3$ indicate high heterogeneity [40].

\section{MICROSCOPICAL EXAMINATION}

\section{Optical microscope}

In a glass tube, $0.2 \mathrm{~g}$ proniosome gel was diluted with $10 \mathrm{ml}$ of $\mathrm{pH} 7.4$ phosphate buffer; a few drops of the formed niosomal dispersion were spread on a glass slide and examined for the presence of insoluble drug crystals using an ordinary light microscope with varied magnification powers $(\times 10$ and $\times 40)$. Photomicrographs were taken using a digital camera [40].

\section{Scanning electron microscopy (SEM)}

The shape, surface characteristics, and size of the proniosomes were observed by SEM. In an attempt to illustrate the role of cholesterol in vesicle formation, the morphological differences in shape and surface characteristics of the prepared proniosome derived noisome of formulae having different cholesterol contents were examined using a scanning electron microscope. In a glass tube, $0.2 \mathrm{~g}$ proniosome gel was diluted with $10 \mathrm{ml}$ of $\mathrm{pH} 7.4$ phosphate buffer; the dispersion was sprinkled and fixed on an SEM holder with double-sided adhesive tape and coated with a layer of gold of $150 \AA$ for 2 min using a Sputter Coater (Edwards, S-150A, England) working in a vacuum of ( $3 \times 10-1 \mathrm{~atm})$ of Argon gas [41].

DSC

This method help to study the possible interactions between drug and vesicle ingredients by taking thermal properties. Thermal properties of the pure drug and the formulation were evaluated by differential scanning colorimetry (DSC) using a diamond (DSC) (Mettler star sw8.10). The analysis was performed at a rate $50 \mathrm{c}$ min- 1 to $200^{\circ} \mathrm{C}$ temperature range under a nitrogen flow of $25 \mathrm{ml} / \mathrm{min}$. Highest EE\% was chosen, and samples of $4 \mathrm{mg}$ of each drug, surfactants, empty and drug-loaded proniosomes-derived niosomes were submitted to DSC analysis. The weighed amount of sample was then held from room temperature to $300^{\circ} \mathrm{C}$ at a rate of $10^{\circ} \mathrm{C} / \mathrm{min}$ [42].

\section{Fourier transforms infrared spectroscopy (FTIR)}

Drug powder was compressed into a pellet along with $\mathrm{KBr}$ using a hydraulic press. The IR spectrum of drug and final optimized formulations were recorded in the wavenumber region of $4000-$ $400 \mathrm{~cm}^{-1}$ on FTIR [42].

\section{IN VITRO RELEASE}

The release study employed the vertical glass Franz diffusion cells which have a diffusional surface area of $1.13 \mathrm{~cm}^{2}$ with the receptor compartment of $10 \mathrm{ml}$ volume [43]. The cellulose dialysis membrane was soaked in distilled water overnight before cutting into suitable pieces. This soaking was conducted to ensure complete swelling of the membrane to provide a constant pore diameter throughout the experiment. The membrane was then mounted between the donor and receptor compartments before filling the receptor compartment with $\mathrm{pH} 7.4$ phosphate buffer. The diffusion cells were incubated into a thermostatically controlled circulator water bath. The temperature of the receptor compartment was maintained at $37 \pm 0.5^{\circ} \mathrm{C}$, and the receiver medium was continuously stirred to prevent any boundary layer effects. Weight amount of proniosomal gels were loaded into the donor compartments; then it was covered with an aluminum foil to prevent evaporation. At predetermined time intervals, namely 1, 2, 3, 4, 6, 8, 12, 18, and $24 \mathrm{~h}$, samples of $1 \mathrm{ml}$ were taken from the receptor compartment and replaced immediately by fresh buffer solution; to maintain the "sink" conditions constantly and a constant volume as well. The samples were then assayed spectrophotometrically. All release experiments were done in triplicates. The plot of cumulative percentage drug release was plotted against time. The obtained release data were subjected to kinetic treatment according to zero, first, Hixson Crowell, and Higuchi diffusion models. The correlation coefficient (r), the order of release pattern was determined in each case.

\section{RATE OF SPONTANEITY (HYDRATION)}

The spontaneity of niosome formation is described as the number of niosomes formed after hydration of proniosomes for $15 \mathrm{~min}$ [44]. Proniosomal gel $(10 \mathrm{mg})$ was transferred to the bottom of a smallstoppered glass tube and spread uniformly. $1 \mathrm{ml}$ of $\mathrm{pH} 7.4$ phosphate buffer was added along the walls of the test tube and kept aside without agitation. After $15 \mathrm{~min}$ a drop of hydrated sample was withdrawn and placed on Neubauer's chamber for counting number of niosomes eluted from a proniosomal gel.

\section{PHYSICAL STABILITY}

Aggregation or fusion of the vesicles as a function of temperature was determined as the change in EE after storage [45]. The vesicles were stored in glass vials at room temperature $\left(37^{\circ} \mathrm{C}\right)$ or kept in a refrigerator $\left(4-8^{\circ} \mathrm{C}\right)$ for 3 months. The retention of entrapped drug and the mean particle size were measured after preparation and then after 1,2 , and 3 months of storage in an optimized formulation. Further, at the end of each month, the samples were also observed for any sign of drug crystallization under an optical microscope. Stability for formulation was defined in terms of retaining its initial EE for 3 months duration. A stable formulation was defined as those showing high EE $(>60 \%)$ and high drug retention value ( $>90 \%$ ), at each time interval.

Drug retained in proniosomes=(Entrapped drug after storage/ entrapped drug before storage) $\times 100$.

Concise evidence of published proniosomal gel formulations and its influence on pharmacology

Astudy by Xu et al. revealed tacrolimus (FK506) for its ophthalmic delivery with a potential approach of proniosome derived niosomes 
with enhanced corneal permeation for effective anti-allograft rejection and ocular irritation. Researchers successfully formulated proniosomes loaded with FK506, incorporated lecithin as a surfactant and poloxamer 188 , cholesterol acts as a stabilizer. With a small amount of ethanol and water in a trace amount, reconstituted to niosomes before to use. Prepared formulation was characterized for morphology, size, and zeta potential, and the surface tension was significantly lowered that enabled easy wettability of the hydrophobic surface of the corneal epithelium contributing for enhanced spreadability and enhanced permeation with high EE and also assessed for its stability. Furthermore, in vitro study on isolated rabbit corneal disclosed permeation of FK506 from niosomes significantly greater than that from control (Protopic ${ }^{\circledR}$ ). Authors suggested that enhanced transcorneal permeation was due to poloxamer 188 and surfactant property of lecithin acted as penetration enhancers, surfactants improved solubility of FK506 significantly and low surface tension, enabled niosomes with desired wetting and spreading properties, and also drug retention studies in the cornea showed significantly high drug retention for the preparation than ointment. They postulated niosomes with the enhanced permeation of FK506 would achieve an effective therapeutic drug concentration for eye diseases through topical administration. Ocular irritation studies revealed no evidence of irritation when compared preparation and saline control group with no statistical difference. Histological investigations showed formulation influence on tissue integrity and corneal cell structure. The results demonstrated superior corneal biocompatibility of the prepared niosomes. In vivo studies were examined for immunosuppressive for topically administrated niosomes, in Wistar and Sprague-Dawley strains of rats. Results showed niosomes treated groups decreased corneal allograft rejection incident with significantly extended corneal allografts survival time when compared with control and blank groups. In conclusion, FK506 niosomes showed potential ophthalmic delivery [46].

Gagandeep Benipal formulated a novel proniosomal system with ketoconazole (KTZ) where non-ionic surfactant (span 60) constituted proniosomes and assured enhanced delivery of KTZ transdermally under occlusive conditions. The author performed various in vitro tests which included encapsulation efficiency, size, and shape; a further formulation was optimized based on in vitro release and stability studies. The formulation showcased high EE, and exhibited vesicle size recommended for efficient transdermal delivery. They had also described the major role of cholesterol and lecithin concentrations for EE of a prepared formulation. From in vitro release studies, the developed proniosomal formulation guided significant protracted release profile compared to a conventional carbopol formulation. Stability studies proposed optimum $5 \pm 3^{\circ} \mathrm{C}$ for storage of the prepared formulation and observed no alteration in EE for the test period of 90 days. In conclusion, proniosomal gel loaded with KTZ exhibited potential delivery system [47].

In another study tazarotene, proniosomal gel was developed by Prasad and Chaurasia, where they developed the proniosomes employing coacervation phase separation composed of stearylamine, span, lecithin, and cholesterol for topical delivery [48]. Span 60 was determined to yield high efficiency for encapsulation. They postulated with high hydrophobicity along with little packing behavior and a minimal amount of cholesterol it yields optimum lamellarity. Authors determined morphological characteristics for proniosomes with goldpalladium sputtered vesicles that were investigated with a scanning electron microscope which revealed well-distinguished vesicles with spherical and sharp boundaries on hydration. Further span 60 with higher HLB values showed smaller vesicles due to reduced surface free energy. Proniosomal gel showed promising in vitro release, and penetration, its release from the formulation was examined by employing pre-conditioned cellulose membrane, latter study was conducted using Franz diffusion cell, taking Wistar rat skin. Results concluded tazarotene release rate was appreciably higher than its flux against rat skin, rendering to barrier properties of skin. Hypothesis indicated drug permeation into the skin, with no significant systemic circulation, provided strong evidence of drug permeation into the skin, efficient for psoriatic therapy. Stability study showed no significant characteristic alterations with vesicular size and encapsulation efficiency of tazarotene for developed preparations at room temperature and refrigeration conditions. Histological examinations of transverse sections of rat tail indicated enhanced orthokeratosis associated with the formulation compared to the control group strengthening the effectiveness of the proniosomal therapy and its advantage for psoriasis treatment.

Miconazole antidermatophytic activity against Trichophyton rubrum was studied by Gupta et al. by loading the drug into proniosomal vesicles. Authors utilized coacervation-phase separation method for developing miconazole preparation by employing cholesterol, surfactants, and phosphatidylcholine [49]. Morphological and structural attributes were investigated using electron microscope yielded good results. They chose macro broth dilution technique for determining the minimum inhibitory concentration (MIC) of the preparation, for the study of pure cultures of Trichophyton rubrum, was considered. An activity of the vesicle gel in terms MIC was assessed against $T$. rubrumby taking different concentrations of preparation in DMSO, which was further incorporated in Sabouraud broth ( $T$. rubruminoculated) in series of test tubes, results were concluded on the basis of turbidity. Furthermore, activity was determined using a disc diffusion method, discs impregnated with test formulation were placed on preconditioned media plates. Results revealed that with an increase in the concentration of miconazole distinct increase in the zone of inhibition. The drug release of vesicular gel determined to be remarkable when compared with control (non-vesicular preparation), and also the antifungal activity of vesicular preparation exhibited a prolonged release of medicament. Finally, the study indicated that developed formula had significant potential for topical delivery against dermatophyte and contributes in terms of efficacious drug delivery.

A recent study by Abdelbary et al. revealed the development of proniosomal gels loaded with KTZ for ocular delivery, where they prepared the gel employing coacervation phase method. Proniosomal gel was prepared by incorporating various nonionic surfactants and maintained a ratio $1: 1 \mathrm{w} / \mathrm{w}$ with lecithin along with a fixed amount $(50 \mathrm{mg}$ ) of cholesterol. Ultimately sufficient amount of water incorporated into the formulation to enable swelling of bilayer resulting in efficient vesicular structures [50]. Significantly highest EE was acquired for a formula with span 65 and lecithin in 1:1 w/w ratio. Authors postulated with an increase in alkyl chain number led to enhanced EE. Concerning proniosomal gel formulated using Brij surfactant, resulted in high EE with Brij 72 and 92, similarly when various grades of pluronics were utilized pluronic L121 showed higher EE. In vitro release studies showed biphasic release profiles for various formulae. An expeditious drug leakage was evident during the initial phase when incubated in a simulated lacrimal fluid, in subsequent phase a protracted release was observed. For Ex vivo, study corneas were isolated from albino rabbits, which were pre-conditioned with simulated lacrimal fluid. Permeability studies were achieved with Franz diffusion cell, where high flux was observed for proniosomes prepared with span 20 , due to its lower transition temperature which enables the proniosomes to be in the fluid state which significantly affects the permeation. The researchers had significantly improved in vivo permeation, with about 20 -fold increase in permeation across the corneal epithelium when compared to control. Furthermore, the test formula did not exhibit any sign of inflammation or alter tear production.

Sathyavathi et al. had formulated a niosomal system for ocular delivery loaded with brimonidine tartrate by thin-film hydration method with various ratios of span and cholesterol, where S-60 and cholesterol in the ratio of $2: 1$ showed high entrapment with extended release. Optimized formula further modified to in situ gelling system, using Carbopol 940 and HPMC to achieve localized action. The preparations showcased pseudoplastic rheology with protracted drug release. The 
formula had shown significant lowered ocular pressure in male albino rabbits compared to marketed drops. Authors concluded that in situ niosomal system had potential applications compared to conventional therapy and enhanced ocular bioavailability [51]

Rita et al. prepared modified proniosomal gel of hydroxyzine hydrochloride with coacervation phase separation technique by screening with various non-ionic surfactants, along with phospholipids. Further the formula variables were optimized with taguchi statistical method. In vitro release study specified that formula with ratio 1:1 of surfactant:cholesterol showed prolonged release furthermore, the interaction of phospholipids with skin lipids retained drug molecule giving a sustained presence at the receptor site and achieve localized action. Similarly, ex vivo permeation study was performed with male Wistar rat's skin, a formulation containing surfactant:cholesterol in the ratio of 1:1 significantly resulted in intact lipid layer and retard drug release and also enhanced the fluidity of the membrane. There was no sign of erythema and edema when tested on rabbit skin also optimized formula retained its stability for 3 months period and concluded refrigeration temperature optimum for storage with least leakage [52].

A transdermal proniosomal gel for Ketorolac was finished by Farooqui et al. from enhanced proniosomal suspension. Ketorolac by transdermal conveyance issues may emerge this can be limited by exemplification it with the new medication transporter. The proniosomes were set up by handshaking technique by dissolving cholesterol and surfactant in liquor; drug was broken up in phosphate cushion saline (PBS) pH 7.4. The PN suspension was kept refrigerated at $4^{\circ} \mathrm{C}$. Carbopol 940 was utilized as a gelling specialist, and dimethylsulfoxide was utilized as entrance improving operator. The consolidation of proniosomal vesicles into the gel base decreased the in vitro medicates discharge from $94.05 \%$. The rate restraint of carrageenan-initiated paw edema $5 \mathrm{~h}$ in the wake of applying the positive control was observed to be $60.00 \%$; the LCI-1-a gel was observed to be $63.44 \%$ while LCI-1-b and LCE-d gel indicated $57.44 \%$ and $49.08 \%$. The LCI-1-a demonstrated promising skin saturation potential, better solidness, and higher ensnarement proficiency than LCI-1-b and LCB-1-g detailing. LCI-1-a demonstrated high medication discharge (94.048\%) more than $17 \mathrm{~h}$ after topical use of upgraded PN plan when contrasted with LCI-1-b, LCB-1-g, and marketed formulation which recommends that PN definition (LCI-1-an) is far way better method of organization of KT through the fundamental dissemination [53].

An examination proposed by Litha Thomas, Vidya Viswanad was to create and factually streamline the proniosomal gel for upgraded transdermal conveyance utilizing $3^{2}$ factorial plans to research the impact of both non-ionic surfactant and cholesterol to expand the entanglement effectiveness and transition Proniosomes were set up by a coacervation method. The last extent of surfactant alcohol aqueous stage was $54 \mathrm{w} / \mathrm{w} / \mathrm{w}$. The investigation demonstrated that the ensnarement proficiency relies on both cholesterol and surfactant while invasion progress depends just on the surfactant proniosomal gel demonstrated a fundamentally upgraded tranquilize pervasion through the skin, with an improvement proportion $3.81 \pm 1.85$ at the point when stood out from the pharmaceutical game plan. The surfactant is an imperative part of the arrangement of niosomal vesicles and the variety in the focus may influence the entanglement effectiveness. The further augmentation in the center from $180 \mathrm{mg}$ to $270 \mathrm{mg}$ reduced the snare capability. The centralization of cholesterol is an essential part of the ensnarement of medication in the vesicles. The watched ensnarement proficiency was expanded fundamentally when cholesterol sum was expanded from $15 \mathrm{mg}$ to $30 \mathrm{mg}$, however, additionally increment in the cholesterol diminished the entanglement effectiveness.

Proniosomal gel demonstrated an essentially improved medication penetrating through the skin, with an upgrade proportion $3.81 \pm 1.85$ precisely when showed up differently in association with the plan outline. Relative evaluation of immersion considers release in vitro examination of redesigned proniosomal gel (F5) with that of displayed gel and carbopol gel showed that the passageway of the enhanced specifying was updated 1.75 times in examination with that of the showed definition and the discharge was controlled. The change contemplates clearly exhibited that catch profitability depends both on the centralization of surfactant and cholesterol and drenching development relies on the gathering of surfactant so to speak, the examination shows that the definition upgrades the skin infiltration of prescription and the pushed separating did not display any plan issues related with it. The gel additionally passes the fleeting dependability ponders, demonstrating the physical and synthetic strength of the item. Consequently, the proniosomal gel is a proficient bearer for the conveyance of clotrimazole, in this manner delaying the activity [54].

An examination proposed by Radha and Chowdary. In conclusion, we can coat that proniosome ornidazole setup goes about as a store structure and shows reliable pharmaceutical release out of all recognizing made investigate 20 without lecithin demonstrates a most crucial measure of the portrayal of game plan inquired about quickly of each elective definition. Ornidazole proniosomal was set up by a coacervation-coordinate division system. When warming each and every one of the fixings was mixed well with a glass bar, the open side of the glass bottle was moored with a cover to store the loss of dissolvable from it and warm finished water shower at $60-70^{\circ} \mathrm{C}$ for around $5 \mathrm{~min}$ till the arranged authority blend was isolated completely. By then the fluid procedure $(0.1 \%$ glycerol approach) was consolidated and warm a water shower until the moment that the minute that a sensible outline was incorporated that was changed over into proniosomal gel on cooling. The gel as requirements be tied down was anchored inside a relative glass bottle in decrease conditions for layout. A blended detailing of traverse 20 and traverse 40 reportable minimum sums sedate embodiment, though in skin penetration contemplates span 20 indicated the high amount of medication pervasion looked at immediately of advertised ornidazole plan. FTIR examines were conveyed and demonstrated that there was no communication amongst API and utilized excipients SEM investigation of streamlined traverse 20 detailing showed that the span of the particles region unit in differing from $3 \mu \mathrm{m}$ to $30 \mu \mathrm{m}$ in the measure. The discharge thinks about for detailing arranged from traverse 20 without lecithin indicated most noteworthy sum sedate arrival of $88 \%$ and traverse 20 definitions demonstrated $84 \%$ of medication discharge for $24 \mathrm{~h}$. Incomparable way traverse 40 and traverse 60 additionally appeared around $70 \%$ of medication discharge, while advertised ornidazole fluid base gel demonstrated just $58 \%$ of medication discharge for 24 long stretches of study. The result of this examination demonstrates that proniosomal ornidazole gel plan is utilized for treating bacterial diseases locally and methodically for a higher medicinal guide [55]

Chandel et al. passed on preparation and assessment of proniosomal gel of neem seed oil using thin layer evaporation method for therapeutic purpose. It is gathered that it is down to earth to set up a satisfactory pronisomal gel of neem seed oil for helpful applications in which used materials are cholesterol, span 40,60, 80, potassium dihydrogen phosphate and toluene, soya lecithin, sodium hydroxide and sodium chloride, and neem seed oil. The proniosomal gel was readied using cross 40, soya lecithin and cholesterol, using neem seed oil as the dynamic pharmaceutical settling. Alcohol and phosphate buffer $\mathrm{pH} 7.4$ were used in the formulation as pharmaceutical excipients. The ensuing subtle elements were evaluated by observing under transmission electron microscopy. Assessment of vesicle measurement and the molecule estimate run was finished utilizing the optical magnifying instrument. Appraisal of formulation yielded appropriate results like uniform size scattering $75-80 \%$ pharmaceutical entrapment and microbiological data. The antibacterial activities of formulations were evaluated by agar well diffusion method. For deciding the percent drug entrapment of proniosomal gel, $25 \mathrm{mg}$ of neem seed oil was hydrated in $80^{\circ} \mathrm{C}$ distilled water and vortexed for $2 \mathrm{~min}$. The niosome scattering so acquired was centrifuged at $18000 \mathrm{rpm}$ for $40 \mathrm{~min}$ at $5^{\circ} \mathrm{C}$ (Remi CPR24 rotator). The clear portion was utilized for the assurance of free medication at $310 \mathrm{~nm}$ spectrophotometrically [56]. 
Das and Kumar made a study to deliver curcumin nano niosomes on skin to treat skin cancer by downregulation of cell proliferative controls involving thymine dimer, apoptosis, transcription factors $\mathrm{NF}-\mathrm{\kappa B}$ and of inflammatory responses involving COX-2, PGE2, and NO and upregulation of p53 and p21/Cip1 which were prepared by reverse phase evaporation and materials used are Tween 65, Tween 60, and glyceryl monostearate as surfactant. Polymers such as carbopolhpmc and the combination of both were used for preparing the gel formulation in which nano niosomes were incorporated. After which gels tested for the spreadability, occlusion, and $\mathrm{pH}$. The drug permeation study was conducted on treated Swiss albino mice abdominal skin and evaluated for anticancer effect. The chemoprophylaxis potential of curcumin was estimated by measuring the tumor burden, tumor volume, tumor incidence, and body weight. Average curcumin particle size was found between 0.0919 um and 1.9961 um measured by Brook Haven 90 Plus particle size analyzer and has its low solubility and physicochemical stability, rapid systemic clearance, and low cellular uptake. In vitro drug release from segregated nanovesicles was completed by dialysis technique in aqueous PEG400 (half v/v) at $37 \pm 1^{\circ} \mathrm{C}$ assessed by UV spectrophotometer at a wavelength of $437.50 \mathrm{~nm}$ [57].

An examination work performed by Preeti et al. The proniosomal gel of terbinafine hydrochloride was finished by coacervation stage detachment strategy. $100 \mathrm{mg}$ of medication alongside settled measures of soy lecithin and ethanol was blended with changed measures of excipient like traverse 40; cholesterol was utilized to get ready and assess the viability of proniosomes. The FTIR contemplates uncovered that there was no noteworthy cooperation of medication with the excipients. The in vitro thinks about uncover that the detailing containing high convergence of soy lecithin and cholesterol had high discharge when contrasted with different plans. The percent entanglement proficiency of all these nine clusters of the arranged proniosomal gel was observed to be 65.11-90.54. The optimized formulation contains Terbinafine hydrochloride (100 mg), span 40 (1350 mg), soy lecithin (900 mg), and cholesterol (250 mg) showed the highest percentage EE $(90.54 \%)$ and slowest drug release in $24 \mathrm{~h}(66.6 \%)$ which indicate the prolonged drug release pattern of formulated proniosomal gel and is also stable for 1 month of period and forms spherical shape niosomes vesicles on hydration [58].

An examination on Proniosomal Gel for Boswellic Acids was performed by Mehta and Meenu, topical definition through the skin requires a non-dangerous, dermatologically adequate bearer, which not just control the arrival of the specialist for draw out activity yet, in addition, improves the infiltration to the skin layer. Boswellic acids have low oral bioavailability due to their lipophilic nature and not solubilizes into the intestinal liquid which restrains its foundational accessibility. High first-pass digestion likewise assumes an essential part in constraining the fundamental accessibility of BAs. Topical details upgrade the conveyance of lipophilic medications and sidestep the principal pass digestion which increments the fundamental accessibility of these medications. Proniosomal gel transporter framework can capture both hydrophilic and also hydrophobic specialists. Boswellic acids can join in the proniosomal gel conveyance framework. By consolidating the emulsifying activity of phospholipids with BAs, the medication and lipid complex gives upgraded bioavailability and enhanced pharmacokinetics. Proniosomal gel in the boswellic corrosive plan will prompt better focusing of medication at tissue goal give provoke beginning and delayed term of activity due to support of viable fixations in the skin in this way boswellic acids bioavailability issues can be survived [59].

An examination on proniosomal gel-interceded transdermal conveyance of bromocriptine (BCT) was performed by Lather et al. To explore the capability of a novel class of vesicular framework "proniosome" as a transporter for a transdermal conveyance of BCT. Proniosome plans were set up by the coacervation phase division technique. In which the proniosomes were set up by coacervation-stage detachment strategy. The $5 \mathrm{mg}$ of BCT mix with soya lecithin and cholesterol were blended with ethanol blend and warmed on a water shower at $60-70^{\circ} \mathrm{C}$ until the point when it broke up. To this blend, phosphate cradle ( $\mathrm{pH} 7.4$ ) was included and warmed a water shower and permitted to cool at room temperature. Diverse evaluations of tweens and ranges were assessed for tranquilizing capture, and last vesicles estimate, percentage EE of the proniosomes was observed to be higher with ranges than with tweens. $90 \mathrm{mg}$ of traverse 60 was picked as the improved sum for the arrangement of proniosomes. An expansion in surfactant fixation after a fitting level encourage the development of the blended micelles which can follow alongside the niosomal vesicles, accordingly indicate expanded size and brought down medication epitome. Proniosomes showed a maintained discharge example of BCT in vitro. Skin saturation examines uncovered high entrance of proniosomes with the supported arrival of BCT through rodent skin. The upgraded proniosomal definition demonstrated the improved transdermal motion of $16.15 \mathrm{mg} / \mathrm{cm}^{2} / \mathrm{h}$ when contrasted with $3.67 \mathrm{mg} / \mathrm{cm} 2 / \mathrm{h}$ for tranquilize scattering. The created details were seen as non-aggravation to the rodent skin and were found as very steady at 4 and $25^{\circ} \mathrm{C}$ for 90 days w.r.t. vesicle size and medication content. The dried proniosomal plan could go about as a promising other option to niosomes and ideally for the transdermal conveyance of BCT. Dry proniosomal gel showed the arrangement of $1.3 \mathrm{~mm}$ measured smooth circular pernicious vesicles after hydration. Traverse 60 was observed to be the most suitable surfactant for the arrangement of proniosomes. Lecithin, cholesterol, and medication were additionally examined and enhanced. Proniosomes displayed 98.9\% of ensnarement productivity and encouraged a managed arrival of embodied medication. The proniosomal detailing enhanced the transdermal transition of medication scattering by 4.4 times when assessed utilizing ex vivo skin pervasion consider. The created definition was observed to be non-aggravation to the rodent skin. The high dependability supports the capability of proniosomes for a fundamental conveyance of therapeutics [60].

Acharya and Kumar formulated candesartan cilexetel proniosomal gel shows increased bioavailability with a novel approach and carried out in vitro - in vivo evaluation studies to the developed formulation. Candesartan cilexetel gel was developed by the slurry method using non-ionic surfactants such as span 60 , tween 60 , and maltodextrin as a carrier followed by cholesterol, and soya lecithin as a stabilizer for preparation of proniosomal gel. Authors prepared dry powder of candesartan proniosomes by taking different concentrations of drug, carrier ratio, dissolved in 2:1 ratio. Methanol, chloroform was added and sonicated for $10 \mathrm{~min}$, adding maltodextrin in the required amount. All the materials were fill in RB flask attached to a rotary flask evaporator to evaporate solvent 60-70 rpm until dry, free-flowing product obtained. Then, resulted from proniosomes hydrated with ph 6.8 phosphate buffer at $80^{\circ} \mathrm{C}$ add $1 \% \mathrm{w} / \mathrm{v}$ carbopol 934 to the niosomal suspension to niosomal gel. The gel was evaluated for the drug content analysis, vesicle size $\mathrm{PH}$ determination, viscosity and rheological studies. In vivo BA studies, conducted by albino rats, blood samples were withdrawn from the tail vein of rats and obtained the pharmacokinetic parameters $\mathrm{C}_{\text {max }^{\prime}}, \mathrm{T}_{\text {max }}$, and AUC $_{-t}$. The concentration levels maintained throughout $24 \mathrm{~h}$, increased relative BA more than the oral route with high of $\mathrm{T}_{\max } 6 \mathrm{~h}$, whereas $4 \mathrm{~h}$ for the oral route. Hence, the proniosomal gel provides longer plasma drug concentration time than the oral route. It is better for the treatment of the hypertension patients. In vitro skin permeation studies carried out for proniosomal gel candesartan using rat skin. It showed higher drug permeation with span 60 than tween 60 due to the larger size of vesicles, less lipophilic nature, and lower skin permeation which make difficulty to penetrate through the skin of tween 60 containing formulation. Better skin permeation, flux, permeability coefficient, enhancement ratio showed formulation $2: 1$ ratio of span 60 , cholesterol. The in vitro release studies profile found to be with biphasic results first $6 \mathrm{~h}$ rapid release followed by controlled release up to $24 \mathrm{~h}$ proniosomal vesicles are smaller in size, with spherical in shape, uniform surface confirmed SEM analysis and there is no aggregation, agglomeration found in a niosomal gel. Better EE with span 60, i.e., 86.7\%, 62.7\% with twee 60 found ph of gel found in the range of 6.7-7.3. Hence, it is a comfort to the physiological acceptance for the topical application. The FTIR spectrum 
confirmed there is no significant change in the chemical integrity of drug and polymers. Optimized formulations were studied for stability studies as per the ICH guidelines, the observed effect of temperature, humidity effect on the gel founded within acceptable limits. Hence, finally the prepared formulation of candesartan proniosomal gel concluded as stable increased BA than the oral dose, delivery of a drug in a sustained manner for an extended period of time, so the formulation is the better option in the treatment of hypertension with better patient compliance and comfort [61].

Another study by Badawi et al., developed dispersed permethrin proniosomesin powder and microemulsion based hydrogel for the treatment of scabies, the powdered proniosomes showed good flow, cyclohexane used as a solvent in preparation, it is less volatile than acetone also added cholesterol, Brij in formulation resulting highest entrapment. Topical proniosome prepared by modified slurry method without vacuum, Aerosil 200 used as insoluble carrier resulted into white color good flow granular powder. Tapped density found to be $0.498 \mathrm{~g} / \mathrm{ml}$, cars index $0.408 \mathrm{~g} / \mathrm{ml}$ and assay of permethrin was $98.2 \%$, and permeation retention of proniosomes was $55.6 \%$. However, unstable at accelerated stability storage conditions. Hence, a base adds to it for topical application for patient convenience and to overcome stability problems. Microemulsion-based hydrogel permethrin 5\% was prepared it was a clear light yellow indicates no crystals present in it. Moreover, it is transparent yellow color shows homogeneity at $97.5 \%$. Stable physically, after 6 months finally authors conclude that proniosomes of the permethrin microemulsion based hydrogel is more effective than powder form and stable one and showed better spreadability, adhesion, viscosity, extrusion, and hydration finally comfort to apply to the patient for the treatment of scabies [62].

Fouda et al. had developed dorzolamide sustained ocular delivery of proniosomal formulation. Coaservation phase separation method was used for the preparation of formulation by utilizing $5^{2}$ full factorial design method. They studied the effect of surfactants (span40) and cholesterol amounts variations (independent variables) on the \%EE, the particle size of prepared formulations. Results showed that the 1:9 ratios of cholesterol and span 40 significantly affect the \%EE. The optimized formulation was selected and carried out intraocular pharmacodynamics study on rabbits, and it was found in the higher reduction in intraocular pressure than the marketed eye drops, i.e., Trusopt. Hence, the final conclusion of this study is dorzolamide proniosomal gel increased the bioavailability and successfully sustained the reduction of intraocular pressure. Dorzolamide proniosomal gel is a very promising drug delivery system used for the treatment of glaucoma disease [63].

\section{CONCLUSION AND FUTURE PROSPECT}

Proniosomal gel contains different kinds of constituents and selection of components need necessitate knowledge because properties of components changing from each other. Which includes surfactant, lecithin, cholesterol, and the role of method of manufacturing have specific advantages which induce quality of final formulation. Thus, the development of stable proniosomal gel purely depending on the suitable ingredients and methodology involved the proniosomal gel preparation is a better comfort, stable and extensively used in drug targeting for controlled release of both hydrophilic and hydrophobic drugs. The gel property of proniosomes maintaining better skin penetration and physicochemical properties. Whereas cholesterol gives stability and permeability to the vesicles by overcomes of, for example, aggregation, fusion, drug leakage, or hydrolysis of the active compounds; therefore, proniosomal gel formulations novel transdermal dosage form is open for research to target specific dermatological as well as other systemic skin disorders. Topical administration of proniosomal gel for the treatment of melanoma, psoriasis, bacterial, and fungal infections can be anticipated successfully by the development of proniosomal gel formulation. More researches are carried out in this field to know the exact potential of this novel drug delivery system.

\section{AUTHORS' CONTRIBUTION}

All the authors were equally contributed to the data collection, information, writing, and critical review helped design of a framework of the document.

\section{CONFLICTS OF INTEREST}

The authors declare that they have no conflicts of interest.

\section{REFERENCES}

1. Bender GA. A history of pharmacy in pictures-great moments in pharmacy. J Am Pharm Assoc 2002;42:170-82.

2. Yuksel N, Bayindir ZS, Aksakal E, Ozcelikay AT. In situ niosome forming maltodextrin proniosomes of candesartan cilexetil: In vitro and in vivo evaluations. Int J Biol Macromol 2016;82:453-63.

3. Kumar S, Singh P. Various techniques for solubility enhancement: An overview. Pharma Innov 2016;5:23-8.

4. Weissig V, Lizano C, Torchilin VP. Selective DNA release from DQAsome/DNA complexes at mitochondria-like membranes. Drug Deliv 2000; 7:1-5.

5. Abhishek VG, Salunhe Ks, Chaudhari SR. Review on self-microemulsifying drug delivery system. Am J PharmTech Res 2015;5:50-66.

6. Vemula VR, Lagishetty V, Lingala S. Solubility enhancement techniques. Int J Pharm Sci Rev Res 2010;5:41-51.

7. Biju SS, Talegaonkar S, Mishra PR, Khar RK. Areview onvesicular systems. Indian J Pharm Sci 2006;68:141-53.

8. Ghulaxe C, Verma R. A review on transdermal drug delivery system. Pharm Innov 2015;4:37-43.

9. Singh Malik D, Mital N, Kaur G. Topical drug delivery systems: A patent review. Expert Opin Ther Pat 2016;26:213-28.

10. Khan R, Irchhaiya R. Noisome a potential tool for novel drug delivery. J Pharm Investig 2016;46:195-204.

11. Saini V, Bala NM, Jhawat V, Kamboj S. Vesicular drug delivery systems: A novel approach for drug targeting. Int J Drug Deliv 2013;5:121-30.

12. Abdelkader H, Alani AW, Alany RG. Recent advances in nonionic surfactant vesicles (niosomes): Self-assembly, fabrication, characterization, drug delivery applications and limitations. Drug Deliv 2014;21:87-100

13. Hu C, Rhodes DG. Proniosomes: A novel drug carrier preparation. Int J Pharm 1999;185:23-35.

14. El Maghraby GM, Williams AC. Vesicular systems for delivering conventional small organic molecules and larger macromolecules to and through human skin. Expert Opin Drug Deliv 2009;6:149-63.

15. Fang JY, Yu SY, Wu PC, Huang YB, Tsai YH. In vitro skin permeation of estradiol from various proniosome formulations. Int J Pharm 2001;215:91-9.

16. Gupta A, Prajapati SK, Balamurugan M, Singh M, Bhatia D. Design and development of a proniosomal transdermal drug delivery system for captopril. Trop J Pharm Res 2007;6:687-93.

17. Kirjavainen M, Urtti A, Jääskeläinen I, Suhonen TM, Paronen P, Valjakka-Koskela R, et al. Interaction of liposomes with human skin in vitro - the influence of lipid composition and structure. Biochim Biophys Acta 1996;1304:179-89.

18. Jiao J. Polyoxyethylated nonionic surfactants and their applications in topical ocular drug delivery. Adv Drug Deliv Rev 2008;60:1663-73.

19. Sinko PJ. Martin's Physical Pharmacy and Pharmaceutical Sciences: Physical Chemical and Biopharmaceutical Principle in the Pharmaceutical Sciences. Philadelphia, PA: Lippincott Williams and Wilkins; 2011. p. 1-1231.

20. Sivaprasad SN, Kumar PL, Srinivas M, Brahmaiah B, Nama S. Proniosome: A novel approach to vesicular drug delivery system. Int $\mathbf{J}$ Drug Discov 2013;3:85-90.

21. Rawat AG. Proniosome gel: Anovel topical delivery system. Int J Recent Adv Pharm 2011:1:1-10.

22. Dheeraj N, Deepshikha KP, Nidhi A. Development and characterization of liposomal drug delivery system for gossypin. Int J Pharm Sci Rev Res 2014;27:11-15.

23. Wilkhu JS, Ouyang D, Kirchmeier MJ, Anderson DE, Perrie Y. Investigating the role of cholesterol in the formation of non-ionic surfactant based bilayer vesicles: Thermal analysis and molecular dynamics. Int J Pharm 2014;461:331-41

24. Yadav K, Yadav D, Saroha K, Nanda S, Mathur P. Proniosomal gel: A provesicular approach for transdermal drug delivery. Pharm Lett 2010;2:189-98. 
25. Sahoo RK, Biswas N, Guha A, Kuotsu K. Maltodextrin based proniosomes of nateglinide: Bioavailability assessment. Int J Biol Macromol 2014;69:430-4.

26. Akhilesh D, Faishal G, Kamath JV. Comparative study of carriers used in proniosomes. Int J Pharm Chem Sci 2012;1:164-73.

27. Kumar K, Rai AK. Development and evaluation of proniosomes as a promising drug carrier to improve transdermal drug delivery. Int $\mathrm{J}$ Pharm 2011;2:71-4.

28. Kumar SP, Kumar NS, Raghuveer I. Proniosome as a sustained drug delivery system: A review. Int J Pharm 2012;3:27-32.

29. Shukla ND, Tiwari M. Pronisomal drug delivery system-clinical application. Int J Res Pharm Biomed Sci 2011;2:880-7.

30. Alsarra IA, Bosela AA, Ahmed SM, Mahrous GM. Proniosomes as a drug carrier for transdermal delivery of ketorolac. Eur J Pharm Biopharm 2005;59:485-90.

31. Walve JR, Rane BR, Gujrathi NA, Bakaliwal SR, Pawar SP. Proniosomes: A surrogated carrier for improved transdermal drug delivery system. Int J Res Ayurveda Pharm 2011;2:743-50.

32. Jukanti R, Annakula D, Errabelli MR, Bandari S. Provesicular drug delivery systems: An overview and appraisal. Arch Appl Sci Res 2010;2:135-46.

33. Perrett S, Golding M, Williams WP. A simple method for the preparation of liposomes for pharmaceutical applications: Characterization of the liposomes. J Pharm Pharm 1991;43:154-61.

34. Blazek-Welsh AI, Rhodes DG. Maltodextrin-based proniosomes. AAPS Pharm Sci 2001;3:E1.

35. Solanki AB, Parikh JR, Parikh RH. Formulation and optimization of piroxicam proniosomes by 3-factor, 3-level box-behnken design. AAPS Pharm Sci Tech 2007;8:E86.

36. Bangham AD, Standish MM, Watkins JC. Diffusion of univalent ions across the lamellae of swollen phospholipids. J Mol Biol $1965 ; 13: 238-52$

37. Jain NK. Controlled and Novel Drug Delivery System. $1^{\text {st }}$ ed. New Delhi: CBS Publishers and Distributors; 2003. p. 270.

38. Khandare JN, Madhavi G, Tamhankar BM. Niosomal novel drug delivery system. East Pharm 1994;37:61-4

39. Vora B, Khopade AJ, Jain NK. Proniosome based transdermal delivery of levonorgestrel for effective contraception. J Control Release 1998;54:149-65

40. Abd-Elbary A, El-laithy HM, Tadros MI. Sucrose stearate-based proniosome-derived niosomes for the nebulisable delivery of cromolyn sodium. Int J Pharm 2008;357:189-98.

41. El-Laithy HM, Shoukry O, Mahran LG. Novel sugar esters proniosomes for transdermal delivery of vinpocetine: Preclinical and clinical studies. Eur J Pharm Biopharm 2011;77:43-55.

42. Couvreur P, Fattal E, Andremont A. Liposomes and nanoparticles in the treatment of intracellular bacterial infections. Pharm Res 1991;8:1079-86.

43. Kumar K, Rai AK. Development and evaluation of proniosome encapsulated curcumin for transdermal administration. Trop J Pharm Res 2011;10:697-703.

44. Consensus Recommendations on Effective Institutional Animal Care and Use Committees. Lab Anim Sci 1987;37 Spec No:11-3.

45. Azeem A, Jain N, Iqbal Z, Ahmad FJ, Aqil M, Talegaonkar S, et al. Feasibility of proniosomes-based transdermal delivery of frusemide:
Formulation optimization and pharmacotechnical evaluation. Pharm Dev Technol 2008;13:155-63.

46. Li Q, Li Z, Zeng W, Ge S, Lu H, Wu C, et al. Proniosome-derived niosomes for tacrolimus topical ocular delivery: In vitro cornea permeation, ocular irritation, and in vivo anti-allograft rejection. Eur J Pharm Sci 2014;62:115-23

47. Benipal G. Design, development, and evaluation of proniosomal gel of an antifungal drug ketoconazole. Int J Pharm Sci Rev Res 2015;31:265-272.

48. Prasad V, Chaurasia S. Performance evaluation of non-ionic surfactant based tazarotene encapsulated proniosomal gel for the treatment of psoriasis. Mater Sci Eng C Mater Biol Appl 2017;79:168-76.

49. Gupta A. Antidermatophytic activity of miconazole nanoformulation against Trichophyton rubrum. Asian Pac J Trop Dis 2015;5:707-10.

50. Abdelbary GA, Amin MM, Zakaria MY. Ocular ketoconazole-loaded proniosomal gels: Formulation, ex vivo corneal permeation and in vivo studies. Drug Deliv 2017;24:309-19.

51. Sathyavathi A, Hasansathali A, Ilavarasan R. Formulation and evaluation of niosomal in situ gel ocular delivery system of brimonidine tartrate. Int J Pharm Sci Res 2012;2:82-95.

52. Rita B, Lakshmi PK. Preparation and evaluation of modified proniosomal gel for localized urticaria and optimization by a statistical method. J Appl Pharm Sci 2012;2:85-91.

53. Farooqui N, Kar M, Singh RP. Formulation and evaluation of proniosomal gel for transdermal delivery of ketorolac tromethamine. Asian J Pharm 2016;10:394-400.

54. Thomas L, Viswanad V. Formulation and optimization ofthe clotrimazole-loaded proniosomal gel using 32 factorial designs. Sci Pharm 2012;80:731-48.

55. Radha $\mathrm{CV}$, Chowdary $\mathrm{CH}$. Formulation and evaluation of ornidazole proniosomal gel. Indo Am J Pharm Res 2014;4:2657-64.

56. Chandel A, Saroha K, Nanda S. Preparation and evaluation of pronisomal gel of neem seed oil. Int J Pharm Sci Nanotech 2012;5:1780-4.

57. Das MK, Kumar R. Development of curcumin nano niosomes for skin cancer chemoprevention. Int J ChemTech Res 2014-2015;7:747-54.

58. Pal P, Mishra SD. Formulation development and evaluation of antifungal proniosomal gel for topical application. World J Pharm Res 2017;6:656-74

59. Mehta M, Garg M. Proniosomal gel: A promising drug carrier for boswellic acids. J Med Sci 2015;15:130-4.

60. Lathera V, Sharma D, Pandit D. Proniosomal gel-mediated transdermal delivery of bromocriptine: In vitro and ex vivo evaluation. J Exp Nanosci 2016;11:1044-57.

61. Acharya A,Kumar GB, Ahmed MG, Paudel S. A novel approach to increase the bioavailability of candesartan cilexetil by proniosomal gel formulation: In-vitro and in-vivo evaluation. Int J Pharm Pharm Sci 2016;8:241-6

62. Badawi A, Elnabarawi MA, Elrehem AR, Fayed BA. Formulation and evaluation of dispersed permethrin proniosomes in powder and microemulsion-based hydrogel bases forthe treatment of scabies. Int J Pharm Pharm Sci 2016;8:221-9.

63. Fouda NH, Abdelrehim RT, Hegazy DA, Habib BA. Sustained ocular delivery of dorzolamide- $\mathrm{HCl}$ via proniosomal gel formulation: In-vitro characterization, statistical optimization, and in-vivo pharmacodynamic evaluation in rabbits. Drug Deliv 2018;25:1340-9. 